\title{
Sokeibelemaye Nwauche and Shawn Teresa Flanigan* Challenges to Nonprofit Organization Participation in Social and Development Policy Planning in South Africa
}

https://doi.org/10.1515/npf-2021-0049

Received September 28, 2021; accepted February 1, 2022

Abstract: In South Africa, government relies significantly on NGOs in the delivery of social services (Patel, L. 2012. "Developmental Social Policy, Social Welfare Services and the Non-Profit Sector in South Africa." Social Policy \& Administration 46 (6): 603-18). The services NGOs provide in areas such as early childhood development, education, health care, skills development, food security, elder care, and other arenas form part of South Africa's framework for achieving its long-term development goals. Also aligned to the United Nations Sustainable Development Goals (SDGs), this government-NGO shared vision for development highlights the importance of NGOs in the development ecosystem. At the policy level, government explicitly refers to NGOs as stakeholders and development partners. However, at the level of practice, questions remain about NGOs' participation in planning for the development to which they so significantly contribute, and the extent of NGOs' role in increasing participation in democratic processes. In an effort to better understand whether NGOs adequately participate in development planning processes in South Africa, semi-structured interviews were conducted with 73 participants, including NGO leaders and relevant key informants from national, provincial and municipal levels of government. The interview data were supplemented with content analysis of government documents. In spite of the fact that NGOs' involvement in development planning is explained by the state as a good governance principle ensuring meaningful participation of stakeholders (Republic of South Africa: Department of Social Development 2017, United Nations Development Programme 2011), the research findings suggest that NGOs' participation in the development planning process is deficient. This deficiency stems from institutional and policy issues including the lack of a framework for participation, government's perception of NGOs and neglect of the NGO sector, and

\footnotetext{
*Corresponding author: Shawn Teresa Flanigan, Professor, School of Public Affairs, San Diego State University, 5500 Campanile Dr, MC 4505, 92182-0001 San Diego, CA, USA, E-mail: shawn.flanigan@sdsu.edu

Sokeibelemaye Nwauche, Postdoctoral fellow, Factor-Inwentash Faculty of Social Work,University of Toronto, Ontario, Canada
} 
political issues such as partisan political activity in spaces of participation and engagement. The democratic potential of NGO participation is also hindered by organizational issues relating to the amorphous nature of the NGO sector, apathy of NGOs and a fragmented NGO sector.

Keywords: South Africa, public participation, policy advocacy, policy planning, government nonprofit partnerships, institutional barriers

\section{Introduction}

Nonprofit organizations (NPOs) have become an integral part of the social policy systems in the different contexts in which they operate. In South Africa, the government relies significantly on NPOs in delivering services (Patel 2012) in various policy fields to address socio-economic problems in communities. The services NPOs provide in various policy fields form part of South Africa's framework for achieving its long-term development goals. In policy statements and documents at the national, provincial, and municipal levels of government, organizations in the South African NPO sector are recognized as stakeholders and essential partners and in the policy development process. However, at the level of practice, questions remain about NPOs' participation in planning for the social policies to which they so significantly contribute.

The policy governance process involves two main aspects, namely: policy formulation/planning and policy implementation (World Bank 1994, xiv). Much literature on NPOs focuses on the vital role NPOs play in the delivery of services and implementation of social policy (Almog-Bar 2017; Frumkin 2002; Levy and Ketels 2021; Okuyama, Ishida, and Yamauchi 2010; Salamon 1995; Salamon and Toepler 2015; Smith and Lipsky 1993; Struyk 2002; Tshiyoyo 2019). Somewhat less attention has been given to service-providing NPOs' participation in the formulation or planning of the social policies and social programs to which they contribute. Involving NPOs in the participatory process for policy formulation provides more opportunities for nonprofits to effectively contribute to policies (Brock 2020). It can also provide opportunities to align government and NPOs' objectives for effective service delivery.

Therefore, the question this article seeks to address is whether NPOs adequately participate in the policy planning process in South Africa. The study focuses on government-initiated engagement with stakeholders within government-created spaces that are akin to Goulet's (1989) state promoted arenas or Cornwall's (2002) institutionalized or formalized invited spaces, for planning purposes. The participation of NPOs in policy planning is analysed through the 
lenses of stakeholder analysis and the concept of participation as a good governance practice in planning.

This article adds to research on the nonprofit sector by identifying barriers that NPOs face in the participatory process of policy planning and gives additional attention to the role of NPOs in social policy formulation within a body of literature that highlights NPOs as social policy implementers. The article contributes to the broader research on government-NPO relationships, showing some constraints to the expressive/advocacy function of nonprofits and their consultation with government (Mosley 2020; Toepler et al. 2020).

\section{Nonprofit Organizations in the Policy Context}

Even though NPOs are viewed as private organizations, their role in delivering services places them in the broader public and social policy space. In many countries, the origins of NPOs have been traced to efforts from individuals and groups within religious and/or secular settings to provide aid and mutual assistance to meet the needs of people within communities (Anheier 2014; Shier and Graham 2014). Ample literature on NPOs in the social and development policy context focuses on their role as a mechanism for service delivery and social policy implementation (Bar-Nir and Gal 2011; Cairns, Harris, and Hutchison 2007; Göçmen 2013; Salamon 1994; Tshiyoyo 2019), whether as faith-based or secular organizations. This role has increased as governments embrace neoliberal policies and decentralize or devolve the provision of services to the private and nonprofit sector (Bar-Nir and Gal 2011; Jiwani 2000; Struyk 2002) through different kinds of partnership arrangements (Casey et al. 2010; Krasnopolskaya, Skokova, and Pape 2015; Salamon and Toepler 2015; Zimmer 1999, 2015) and service contracting (Struyk 2002; Zhu, Zhao, and Tao 2021).

NPOs also play a role in the policy context by engaging in advocacy and drawing attention to the inequalities and social problems (Kendall and Knapp 1993). In South Africa, De Wet (2010) indicates that in addition to service provision, NPOs act as watchdogs over government and public sector administrators. They also promote good governance (Mafunisa 2004). Thus, Mafunisa (2004) argues that the effectiveness of governmental institutions in addressing development problems such as poverty, crime, disease, and high rates of illiteracy will only be possible if NPOs are allowed to participate in the policy-making processes.

Lest these problems seem unique to the global South, it is important to keep in mind that barriers to policy advocacy are common among service providing organizations in the global North as well, noted by researchers in Europe (Verschuere and De Corte 2015) and North America (Brock 2020; Flanigan 2011; Jiwani 
2000; Nicholson-Crotty 2007). While acknowledging the importance of NPOs in service delivery and policy implementation, this article examines the role of NPOs in the formulation of the policies that NPOs contribute to implementing.

\section{Stakeholder Analysis}

The concept of stakeholder has a variety of definitions. Freeman $(1984,53)$ defines a stakeholder as "any group or individual who can affect or is affected by the achievement of an organization's purpose”. Stakeholders are also defined as individuals, groups, and other organizations who have an interest in the actions of an organization and the ability to influence it, with a potential to threaten the organization and potential to cooperate with it (Savage et al. 1991). Although traditionally stakeholders have been analysed through the prism of their economic function to the firm, stakeholder claims can be examined through other societal compositions that are not economic or market-oriented (Crane and Ruebottom 2011). From a policy formulation and practice perspective, Grimble and Wellard (1997) define stakeholders as any group of people, organized or not, of any size or aggregation, who have a common interest in a particular issue or system at any societal level or position. This can be from the global, national, or regional level down to the micro household and intrahousehold level. These groups include public, private, and civil society organizations that exist and interface with communities (Lyon, Hunter-Jones, and Warnaby 2017).

In each of the descriptions, we can conceptualize NPOs and their constituencies as stakeholders, thinking of the 'firm' or 'organization' as represented by the state. The utility of analysing NPOs as stakeholders is rooted in how NPOs' services affect social policy objectives in the contexts in which they operate. Understanding of the kind of stakeholders that exist facilitates stakeholder salience, which is how, why, and the extent to which the stakeholder is prioritized and given attention (Mitchell, Agle, and Wood 1997). If NPOs are treated as stakeholders as described in South Africa's development planning policy documents, we should expect to see ample participation and consideration of NPOs in policy formulation.

\section{Participation and Development Planning in South Africa}

There is hardly a precise definition of the term 'participation' (Goulet 1989). However, as an element of good governance in the broader development governance process 
(others being transparency, strong institutional capacity of the public sector, public sector accountability and the rule of law) (World Bank 1994, xiv), the World Bank defines participation as having "influence on development decisions, not simply involvement in the implementation...” (World Bank 1992, 27). Participation increases the voice of stakeholders, citizens and users in the design and implementation of projects and programmes (World Bank 1992). The World Bank definition is central to the conceptualization of participation in this article.

Participation in the planning process is conceived of as an alternative to and a reconfiguration of traditional top-down development management systems (Brett 2003; Cornwall 2002). It is also a moral incentive that allows citizens to negotiate and gain entry into the arenas of decision-making (Goulet 1989). Cornwall (2002) conceptualizes participation as a spatial practice that occurs in diverse and multiple arenas in which a wide array of actors is active, noting that (1) spaces for participation are created, (2) they are shaped, in terms of who initiates, constitutes, facilitates, and chooses the methods for participation and (3) the actors who make and shape the spaces determine who occupies those spaces. He makes a distinction between institutionalized/formalized spaces and non-formalized spaces. The institutionalized spaces, also referred to as invited spaces, are forums where the authorities and the people meet. These kinds of space are, essentially, part of the governance machinery. The non-formalized spaces are chosen and occupied by citizens, groups, and associations, and are autonomous from the state. Thus, they are referred to as 'claimed spaces' (Gaventa 2004, 35) or 'invented spaces' (Kersting 2013, 271). This article is concerned with the invited formalized spaces created by the state.

In South Africa, participation is a mandated process for policy planning. The participatory process is lauded as one of the hallmarks of planning in South Africa. It involves the creation of forums and formal mechanisms to secure consultative and participatory processes to gain inputs from different stakeholders. These include citizens, government representatives, the social sector (including organizations in the non-profit sector), and the private/business sector to discuss and analyse developmental challenges and set priorities (Republic of South Africa 2018 , n.d). The participatory process, therefore, provide avenues for government to interact and engage with citizens and relevant stakeholders in a dialogical process.

From the National Development Plan (NDP) to provincial development plans, down to the integrated development plans (IDP) of municipalities, engagement and consultation with diverse groups and stakeholders are projected as a vital process in planning. However, it is important to note that participation is legislated only at the municipality level, as outlined in the Municipal Systems Act. The Act outlines the procedures and process for community participation for the formulation of the IDP. It defines "community" as comprising of the residents of the 
municipality, ratepayers and civic organizations and non-governmental, private sector or labour organizations or bodies which are involved in affairs within the municipality (Republic of South Africa 2000). In terms of mechanisms, processes, and procedures to facilitate participation, the Act stipulates that the municipality must encourage and create conditions for the community to participate. For example, community participation must take place through political structures (such as the ward and IDP Representative Forum at the municipality level) and the municipality must communicate information about the time, date, and venue for public or consultative meetings with members of the community and community organizations.

In practice, however, participation in development planning in South Africa looks quite different from what is described by law. Buccus et al. (2008), for example found that planners and government do not pay sufficient attention to existing institutional frameworks and mechanisms for engagement and community participation in development planning. This view is also shared by Williams (2005), who notes that community participation is not driven by the legislated IDP process. Consequently, the extent to which stakeholders are given the opportunity to effectively participate in decision-making processes are unsatisfactory (Murombo 2008). Also, Piper and Nadvi (2010) note that statecreated spaces for engagement in communities in South Africa are often dominated by political parties and their attendant party politics. As such, organizations in the non-profit sector, especially those involved in service delivery, tend to disengage from the state.

Given the juxtaposition between the legislative context of participatory planning in South Africa and the social and political climate in local communities, this article seeks to address whether NPOs adequately participate and the challenges to their participation in the policy planning process in South Africa. The mechanisms and procedures present in South Africa's national, provincial, and municipal planning process match well with three main categories of participatory processes discussed in the extant literature, which include mechanisms to secure stakeholders/participants, spaces or forums for participation, and mechanisms for conducting the participatory process. These categories allowed for an analysis of participatory planning for development in South Africa.

\section{Method: Sampling and Data Collection}

This study used a qualitative approach to explore whether NPOs adequately participate in policy planning processes in South Africa. In South Africa, NPO is a legal form under which "a trust or other associations of persons established for a 
public purpose" (NPO Act, Section 1) can register, as we limited the analysis to these legally registered organizations. Qualitative data were collected from respondents at the national level in Tshwane (which is the capital of South Africa), the Western Cape Province, the Eastern Cape Province, and five municipalities within the two provinces. The respondents were sampled purposively and through the snowball sampling method. The respondents include NPO leaders (including officials from NPO coalition groups) and relevant policy actors (designated as key informants [KIs] from national departments in Tshwane (National Planning Commission and the Department of Social Development), provincial departments, and municipality IDP office involved in policy planning).

The main purpose of sampling respondents from Tshwane is because it is the capital and the seat of the national government. The Eastern Cape Province represents the east of the country and the Western Cape the west (and southern part). It is important to note, however, that provincial planning is guided by a provincial planning framework and municipality planning by the IDP. So, procedurally, planning within each sphere of government is mostly uniform but the plans are tailored to reflect the specific contextual conditions of the provincial or local needs a specific province or municipality. Collecting data in the different sites was not for the purpose of recruiting a representative sample or for generalization, but to gain insights from the participatory process in different contexts. This also provided the opportunity to explore if in practice there are possible divergences in NPOs participation in the different research sites.

Semi-structured interviews were conducted with 73 respondents comprising thirty-eight policy officials and thirty-five NPO leaders between 2018 and 2019. Of the thirty-eight KIs, four were from the national level, 10 from the provincial level, and 16 from the municipality level. The interviews lasted between $29 \mathrm{~min}$ and $1 \mathrm{~h}$ $20 \mathrm{~min}$ and were audio-recorded. The respondents were asked questions about the procedures and mechanisms for engagement between government and NPOs, and the involvement of NPOs in the planning process. This included information such as the respondents' knowledge of participatory meetings, how information about the consultative process is disseminated, if and how invitations to meetings are made, who is invited to meetings (actors) and where the consultations occur (spaces), how participatory processes are organized, and issues that are discussed.

Data collection continued until theoretical saturation was achieved, meaning additional data did not make an additional significant contribution to the development of codes or categories (Glaser and Strauss 1967). This does not indicate that a researcher has learned everything that could be known in a substantive area, but that gathering additional data no longer provides new ideas or sparks new insights (Charmaz 2006). The interview data were supplemented with information from government documents and field notes taken from three IDP Representative 
Forums. Three IDP Representative Forums were attended, twice in Nelson Mandela Bay Municipality (NMBM) (2018 and 2019) and once in Amathole District Municipality. The meetings lasted for an average of $2 \mathrm{~h} 30 \mathrm{~min}$ on each occasion. The forums were at the instance of the mayor of the respective municipalities, and the participants comprised mostly of municipality officials, councilors, and representatives from different wards in the municipality. In the 2019 forum at the NMBM, one participant introduced himself as an executive of a coalition of NPOs but was attending the meeting as a community member from a ward with a persisting problem of burst water pipes. No other participant identified as an NPO leader or employee in all three meetings. The document analysis and field notes were used to validate the qualitative interview data.

\subsection{Data Analysis}

The data were transcribed verbatim and analysed using thematic analysis. Thematic analysis involves analysing, identifying, and presenting patterned meaning or themes within a dataset (Boyatzis 1998; Braun and Clarke 2006). Thematic analysis allows researchers to identify patterns across data using an inductive approach, where coding and the development of themes are led by the content of the data, or a using a deductive, theory-led approach where coding and development of themes are organized around existing concepts but the researcher remains open to new ideas that emerge (Braun and Clarke 2006; Joffe 2012). This analysis used a deductive approach, though some categories were also developed inductively. The data was analysed manually to allow for grasping of the complexity and contextuality (Muhr 1991) of the process being studied.

Taking a deductive approach, the coding process was guided by the literature on procedures and mechanisms for participation, with a focus on 1) mechanisms to secure stakeholders/participants, 2) spaces or forums for participation and 3) mechanisms for conducting the participatory process. The analysis yielded three categories: lack of adequate procedures for invitation to participate, exclusionary entry points for engagement, and inequitable methods of participation. These were aggregated into the theme "deficient institutional arrangements", which hinder NPOs' participation in policy planning. The category lack of information on NPOs emerged inductively and was incorporated into the theme "deficient institutional arrangements". The inductive analysis yielded two additional categories, unorganized sector, and partisan politics. These were aggregated into the theme "underlying contextual issues", which also hinder NPOs from adequately participating in the planning process. 


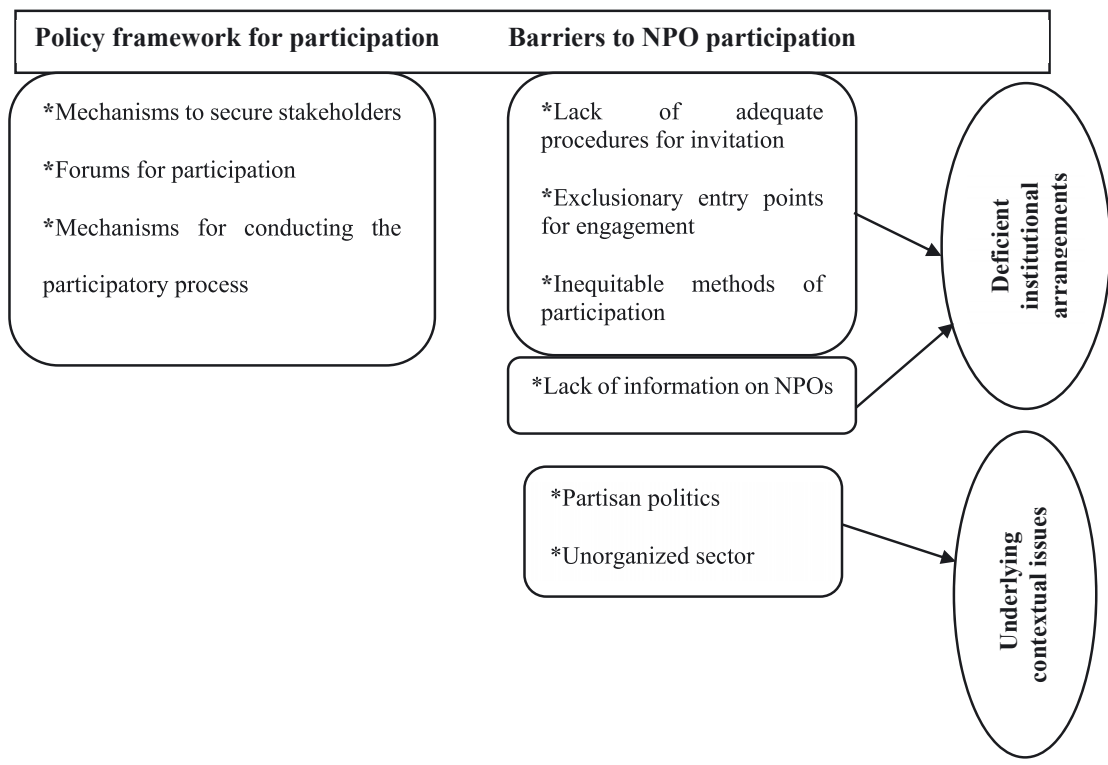

Figure 1: Barriers to NPOs participation in policy planning.

\section{Findings}

The findings suggest that deficient institutional arrangements for participation and other underlying contextual issues work in concert to hinder NPOs from participating in policy planning, as indicated in Figure 1.

As Figure 1 illustrates, even though a policy framework for participation exists, the reality on the ground in South Africa makes policy participation by NPOs quite challenging.

\section{Deficient Institutional Arrangements}

Deficient institutional arrangements refer to the inadequacies in institutional frameworks that deter NPOs from sufficiently participating in policy planning.

\subsection{Lack of Adequate Procedures for Inviting NPOs to Participate}

The interview data show a weakness in procedures for inviting NPOs into the participatory process at various levels of government. Policy officials would argue 
that planning is a collective process with consultation across a broad range of stakeholders, including the non-profit sector. However, when questioned about specific procedures for the participatory process, especially as it relates to NPOs, inadequacies became apparent. Often, government officials admitted there was no particular process for inviting NPOs to participatory meetings, especially at the national and provincial level. As indicated by some key informants:

[...] I think there has been an on-going difficulty, particularly at the provincial level about how to engage strategically with the organizations. The strategic problem is that, unlike the local government where you've got IDP [Integrated Development Plan] process ... the provincial government doesn't really have this same kind of mechanisms. So, we don't have a platform at the provincial level where we just meet with people and organizations to pace their thinking on things. (KI, provincial level)

I don't think that we can say that we consult with every organization ... At the national level it would always be challenging, to have an aggregate situation, but at the local level is where they can meet councillors and different levels of provincial representatives. (KI, national level)

Even though policy officials suggests that it would be more feasible for NPOs to participate at the municipal level because the procedures for participation are outlined in the Municipal Systems Act, the procedures are not properly implemented to incorporate the NPO sector into participatory processes at that level either. Some NPO leaders who reside in the communities where they operate indicated that they get invited to IDP ward meetings, but they are invited in their capacity as residents and not as operators of a NPO in the community. As one NPO leader explains:

In the [ward] IDP meeting we get invitations from the councillor, but we just go like normal community members. We participate as community, not as ' $\mathrm{Y}$ ' [name of organization]. If they can invite us as ' $\mathrm{Y}$ ' organization, not as a community member so we can give them our view as $\mathrm{Y}$, since we work in the community. (NPO leader)

Though participation is legislated at the local level, invitations to participate are not better implemented at the municipal level of government than at the national and provincial levels of government.

The lack of adequate procedures for inviting NPOs has other consequences, such as government planning without community input, or not inviting NPOs or inviting them to participatory meetings at the last minute. Some NPO leaders indicated that:

[The national] Government does not invite us. We have been saying this for a number of years, that we want to work together for the sake of improving the quality of life of children and all vulnerable groups in this country, but we do not get that. We don't want government alone to 
talk, but rather invite us to these meetings where you plan because we are hands-on on the ground. (NPO leader)

Sometimes they [the municipality] deliberately don't invite us, or I will get an invitation for an event the day before it happens or in the morning and it's almost like it's part of the exclusion strategy because, they know that you are never going to make it. So, the way people are invited is also very interesting and then it is said that we are invited, but we don't come. (NPO leader)

In other circumstances NPO leaders feel they are provided with fewer opportunities than other sectors to participate in planning:

The NEDLAC ${ }^{1}$ arrangement, it's failing when it come to the sector because it always promotes business and labour in their talks [...] This platform is a platform that is meant to extend engagement from that national strategic level between state, labour and business and the social sector. As it stands now, we have a seat, only by invitation and not all the time, whereas business is full-time, government is full-time, labour is full time. (NPO leader)

Some NPOs indicated that in addition to the irregularity of invitations to participate, those organizations that are invited, often are larger organizations that do not necessarily represent the sector.

\subsection{Exclusionary Entry Points for Engagement}

The data suggest that another hindrance to the participation of NPOs in the policy planning process is that there is no specific or legislated space(s) for engagement between the NPO sector and policy officials. While there seem to be various spaces, or what we refer to as entry points for engagement, within departments at different levels of government akin to the formalized but transient spaces identified by Cornwall (2002), the spaces are exclusionary. They are exclusionary in the sense that participation within these spaces is mostly with government-funded organizations and with large or 'well-known' organizations. As one interview participant explain:

We are an umbrella coalition for more than one hundred NGOs, but the government has set up parallel structures to communicate with some NPOs. They [provincial Department of Social Development] call it NPO District Forums. They are not willing to receive any engagement from any other structure besides that particular structure and not everybody is invited to that structure. So, if you are a non-funded NPO, not funded by Department of Social Development, the chances of you being invited there is hardly likely. (NPO leader)

1 National Economic Development and Labour Council (NEDLAC) is a forum for engagement at the national level for government's engagement with different sectors. 
The implication of this is that, if an NPO is not being funded by any government department or is not a well-known organization, the chances of having the opportunity to be invited into any entry point for engagement is slim. This exclusionary pattern of participation in the planning process deprives smaller organizations, which constitute the majority of NPOs in South Africa, from making inputs into policy. It also excludes NPOs that generate funds from sources outside of government. This amounts to insufficient opportunities for NPOs to participate.

\subsection{Inequitable Methods of Participation}

The inequitable methods adopted for the participatory process also present hindrances to NPOs' participation in policy planning. Pre-designed policy agendas are seemingly foisted on NPOs in participatory meetings in a way that does not provide much room for NPOs to give input into policy. Some NPO leaders express concern that NPO participation is just formality and to tick a box, and not necessarily a process meant to provide adequate opportunity for government-NPO interaction. This is because policy actors come to meetings with a pre-designed agenda or blueprint of what will be discussed, without leaving much room for other stakeholders (in this case, the NPOs) to give their input. As some interview participants explain:

I think there is a lot of lip service, a lot of it is around, 'We value your input', you know. That's why I've stopped going ... So, for me it's almost like, this whole thing about consultative process [in the municipality], when they arrive it's a forgone conclusion that whatever it is they were saying has already been decided. (NPO leader)

We need to talk about invited platforms. You invite me, you've already got an agenda. When do I come to a meeting where I can bring my agenda? So, my points are never ever heard because you already have an agenda and so the entire meeting is about you telling me about your agenda. (NPO leader)

These meetings, as such, are considered by NPO leaders to be merely information sessions and not pathways to meaningful participation in the policy planning process. This institutional deficiency also exists within funding partnerships, where government funded NPOs are invited to meetings mainly to be informed of the funding government entity's objectives, which they require the given NPO(s) to achieve. One NPO leader notes:

We are not called to any planning meetings. [The provincial] Department of Health or Social Development; they plan, and they give the plan to us as in, 'This is what we want to achieve; this is what you must achieve'. (NPO leader) 
This kind of approach to planning perpetuates the thinking that NPOs are only suited to implementing programs on behalf of government and less deserving of a seat at the table where the planning of the program occurs.

Some government employees counter that public meetings are not the only means of participation; for example, feedback on policy documents can also be helpful participation. A policy planner noted:

If we talk specifically about policy making, they (the NPOs) come in at some point. They will have an opportunity, in terms of when a policy document has been developed to make input into that policy. So, we will give them a time to comment on that policy (and) provide inputs. (KI, municipality level)

While it can be argued that having the opportunity to critique policy documents is a form of consultation, NPO leaders argue it is not enough. Like holding meetings with a pre-arranged agenda, some NPO leaders are adamant that this does not provide them adequate opportunity to engage with the government and give their input into a policy plan. Rather, it is considered a perfunctory gesture that serves to simply check the boxes, as the policy has already been largely developed, and there is no guarantee that their input will eventually make it into the final policy document.

\subsection{Lack of Information on NPOs}

Non-profit organizations in South Africa operate in a fluid environment in which there is a lack of comprehensive databases or systematic processes for generating information on the NPO sector. This presents challenges for state-NPOs interaction in the policy planning process. As NPOs are considered stakeholders in the development process, in order to invite them into entry points for engagement, government needs to be able to identify who is doing what and where. The lack of efficient systems to generate comprehensive information on the organizations in the NPO sector creates challenges of properly identifying current and active organizations and inviting them into spaces for participation. Even though the national Department of Social Development (DSD), which is responsible for the registration of NPOs, keeps a database of registered organizations, that information is hardly accurate. As interview participants describe:

It's actually a big problem because nobody really knows, at any point in time, the actual size and shape of the sector ... we can't rely on that database at all ... So, there are thousands and thousands of organizations on that database, but it's not a true picture of what the sector actually looks like and it's an issue because that would actually be useful information as well for planning. (KI, national level) 
I cannot pinpoint to a database or maybe one centralized database where you can go and get all of them. But what I know is that ... there is a whole lot of SLAs [service level agreements] with different agencies where they keep this information. (KI, municipality level)

It is important to note that the database in the DSD is used mainly to enable NPOs to retain their legal status and not for planning purposes. The data is not necessarily shared with other national departments, provincial and municipality planning offices, or other departments. Also, different levels of government have different databases without any mechanisms to consolidate information, resulting in the existence of numerous fragmented databases mostly documenting funding partnerships. One KI summarised the scenario like this:

Those we don't have a relationship with, we don't know about those ones. Those that we have a relationship with, we get the stats and data from them. (KI, municipality level)

The lack of mechanisms for generating information present challenges for adequately identifying NPOs and knowing who is doing what, where, and how, making it difficult to invite NPOs and provide opportunities for participation in the planning process.

\section{Underlying Contextual Issues}

Underlying contextual issues are issues that are outside of the institutional framework for participation in policy planning but within the context in which NPOs operate, which also constrain them from participating adequately in policy planning. These include partisan politics and an unorganized NPO sector.

\subsection{Partisan Politics}

Partisan politics can become infused into spaces for participation and engagement with government. This is especially common at the local government level, creating a particularly inconducive space for interaction and participation in the policy planning process. Creating spaces for dialogue is important, but the nature of the space for interaction also matters. The co-optation of these spaces by partisan politicians hinders NPO leaders from actively participating in the consultative process and engaging in dialogue on their services in the planning process. As some NPO leaders note:

Generally, these organizations as I know them, they don't want to be trapped into issues of politics and fighting. They will not want to form part of those meetings, and consequently 
withdraw from them. In turn the whole thing frustrates the supposedly constructive engagement and focused input for development [in the municipality], and it will end up being a domain for party politicking, not development ... So, obviously you will just say, 'Let me go to my NGO and not worry about these structures' (NPO leader).

The developmental context, you realize that it is highly political, and you have to play safe so that you don't become associated into the political dimension ... so, for example, Tshwane [municipality] has a $\mathrm{DA}^{2}$ mayor, it means that when you go to that meeting of the mayor, you are surely going to be coloured a bit by the political agenda of the DA ... The premier [of the province] is ANC, ${ }^{3}$ going to some of the meetings, you as surely likely to be kind of contextualized in the agenda of the ANC, which is very tricky. So, what do you do? (NPO leader)

NPO leaders conceive of space(s) for participation as politically "contaminated" because the atmosphere is sometimes contentious. Therefore, even when the opportunity to participate presents itself, NPO operators tend to avoid spaces for participation in to remain neutral and steer clear of partisan politics. This translates to missed opportunities for participation and engagement with government in the planning process.

\subsection{Unorganized Sector}

The unorganized nature of the nonprofit sector itself also serves as a hindrance to NPOs' participation in policy planning. The data suggest that the NPO sector operates in such an uncoordinated manner that they are unable to effectively mobilize to gain government's attention, either through coalitions or representation. For example, some respondents indicated:

It's inherently a hard sector to draw a line around, about who speaks on behalf of whom. There is a lot of contestations in the sector and it's almost always difficult to say whether you've spoken to enough organizations to say you actually have a representative sample. So, I think that is one of the technical challenges for government: knowing how to engage with a sector that is quite amorphous. There is not a lot of internal coherence or a single view on anything. Unlike business or labour where the mechanisms are much clearer about how to engage with them. (KI, provincial level)

The reality is that government [at different levels] has capitalised on our fragmentation, and they use it. So, the more fragmented and divided we are, the more we cannot bring our voices together as a collective to engage government. (NPO leader)

2 Democratic Alliance is the main opposition political party to the ruling party in South Africa.

3 African National Congress, the ruling political party. 
The unorganized nature of the sector, thus, manifests as a fragmented and uncoordinated sector with organizations working in silos. Such a sector also seems challenging to invite into spaces of participation. Especially with a decline in available funding, NPOs seem to pursue their own mission and agenda with less interest in collaboration. NPOs are unable to organize themselves into a coherent force of relevant stakeholders that government engages seriously as not only in programme implementation through contracting and grants, but as co-creators of programmes that address problems in communities. The unorganized nature of the sector, therefore, reduces opportunities for participation in the planning process.

\section{Discussion and Conclusion}

This study aimed to examine the challenges to NPOs participation in the development planning process in South Africa. The findings suggest that NPOs do not participate adequately in the policy planning process due to challenges of deficient institutional arrangements relating to how NPOs are invited, the exclusionary nature of spaces for participation, inequitable methods of participation and a lack of adequate information about NPOs. Other factors that present challenges to the participation of NPOs include underlying contextual issues such as partisan politics and the unorganized nature of the sectors. This suggests that even though NPOs are intrinsically linked to the public and/or social policy of the contexts in which they operate due to their service provision, they do not participate adequately in influencing the policies they implement. Rather, they are mostly considered as service providers and policy implementers. The asymmetric focus on NPOs as gap fillers, service deliverers and policy implementers paints only half the portrait of their relevance in the policy process.

NPOs typically derive their vision for addressing societal needs from their own perspective. Bringing NPOs into the dialogical and participatory process for planning can provide opportunities for alignment between NPOs' objectives and government's plans for addressing social problems within communities. There is, therefore, a need to bring NPOs into the participatory process of planning. In other contexts, Salamon et al. (1999) also identified the need for the state to make room at the table for NPOs in public spaces for policy formulation. As the findings suggest, in South Africa, the deficiencies in the institutional frameworks for participation create challenges to NPOs participation. While these processes are less well defined at the national and provincial levels, participatory procedures that incorporate NPOs at the municipality level are poorly implemented. This lack of an organized procedure for the participation of NPOs indicates the 
presence of an institutional void in the planning process in South Africa (see Nwauche and Claeyé 2019).

This article further argues that the participation of NPOs in planning will be more effective at the local level and can be used as a scaffold to build up to the provincial and national level. According to the wall-to-wall municipal system in South Africa, every geographical space in the country is within a municipality. The implication is that every NPO operates within a municipal space, whether the organization is big or small, local, or international, funded by government, led by community leaders or by those from outside the community. Given that the NPO database is held by the Department of Social Development, which is responsible for the registration of NPOs, this also means that NPOs can be more easily accessible to policy planners in municipal spaces. Policy planners can generate information on this stakeholder group and understand their salience and the nature and scope of their services to engage them in the planning process. At the operational level, it can also address inequitable methods of participation.

Furthermore, the contextual hindrances to NPOs' participation, as identified in this article, are a reminder that spaces for participation are not neutral (Cornwall 2004). As such, the nature or character of the entry points for engagement can influence people's decision to participate. Thus, the infusion of partisan politics into spaces for participation in South Africa dampens the interest of NPOs in joining the participatory process and consequently causes them to withdraw from the entry points of engagements. This translates to missed opportunities for participating in the policy planning process.

Secondly, the contextual hindrances suggest that the behaviour of actors within a context can influence their relevance and relationship with the state and policy actors. Therefore, the lack of coordination and collective engagement with policy actors that results from an unorganized sector constrain adequate participation of NPOs in planning. Also, the perception of NPO leaders of themselves in relation to the context in which they operate presents challenges to their participation. Nonprofit organization leaders who are not from the community in which they provide services tend to view themselves as outsiders. As such they are less willing to engage with the institutional bodies and participate within the local context than NPO leaders who are from the community. This is also a function of and further exacerbates the lack of collective engagement of NPOs with policy actors. The barriers to NPOs' participation in policy planning, thus, suggest that the role of NPOs in the policy context is not being fully harnessed. As their services affect the achievement of the country's social policy, it calls into question the true meaning of NPOs as stakeholders in the policy process in South Africa.

To create pathways and make space for NPOs in the policy planning process, there is a need to address the issues that hinder NPOs. First, it is necessary to 
develop and effectively implement policy procedures that will enhance NPOs' participation in policy planning. Also, it is crucial to minimize the infusion of partisan politics into spaces for participation for NPOs, for example by paying attention to the configuration of actors that are allowed into the spaces and the types of discourse permitted in the space. The proper management of such spaces can promote productive participation. Furthermore, while the authors recognize that NPO leaders are diverse in their ideology about engagement with the state and that some organizations are more willing and able to engage than others, the sector needs to find ways of organizing within collectives and coalition groups. This is because, for practical reasons, government cannot engage with every organization individually. It would be more practical to gain attention as groups. The issues addressed in this article can be relevant in other contexts outside of South Africa, especially in an era that emphasizes intersectoral relationships and cooperation between state and non-state actors for effective policy governance.

\section{References}

Almog-Bar, M. 2017. "Civil Society and Nonprofits in the Age of New Public Governance: Current Trends and Their Implications for Theory and Practice." Nonprofit Policy Forum 8 (4): 343-9.

Anheier, H. K. 2014. Nonprofit Organizations: Theory, Management, Policy, 2nd ed. New York: Routledge.

Bar-Nir, D., and J. Gal. 2011. "Who Has the Power? The Role of NPOs in Local Authorities." Voluntas: International Journal of Voluntary and Nonprofit Organizations 22 (1): 1-25.

Boyatzis, R. E. 1998. Transforming Qualitative Information: Thematic Analysis and Code Development. Thousand Oaks: Sage.

Braun, V., and V. Clarke. 2006. "Using Thematic Analysis in Psychology." Qualitative Research in Psychology 3 (2): 77-101.

Brett, E. A. 2003. "Participation and Accountability in Development Management." Journal of Development Studies 40 (2): 1-29.

Brock, K. L. 2020. "Government and Non-Profit Collaboration in Times of Deliverology, Policy Innovation Laboratories and Hubs, and New Public Governance." VOLUNTAS: International Journal of Voluntary and Nonprofit Organizations 31 (2): 257-70.

Buccus, I., D. Hemson, J. Hicks, and L. Piper. 2008. “Community Development and Engagement with Local Governance in South Africa.” Community Development Journal 43 (3): 297-311.

Cairns, B., M. Harris, and R. Hutchison. 2007. "Sharing God's Love or Meeting Government Goals? Local Churches and Public Policy Implementation.” Policy and Politics 35 (3): 413.

Casey, J., B. Dalton, R. Melville, and J. Onyx. 2010. "Strengthening Government-Nonprofit Relations: International Experiences with Compacts." Voluntary Sector Review 1 (1): 59-76.

Charmaz, K. 2006. Constructing Grounded Theory: A Practical Guide Through Qualitative Analysis. Thousand Oaks: SAGE Publications.

Cornwall, A. 2002. Making Spaces, Changing Places: Situating Participation in Development. IDS Working Paper 170. Also available at https://opendocs.ids.ac.uk/opendocs/bitstream/ handle/20.500.12413/3932/Wp170.pdf. 
Cornwall, A. 2004. "Spaces for Transformation? Reflections on Issues of Power and Difference in Participation in Development." In Participation: From Tyrany to Transformation? Exploring New Approaches to Participation in Development, edited by S. Hickey, and G. Mohan, 1-30. London: Zed Books.

Crane, A., and T. Ruebottom. 2011. "Stakeholder Theory and Social Identity: Rethinking Stakeholder Identification.” Journal of Business Ethics 102 (1): 77-87.

De Wet, J. P. 2010. “On the Horns of a Dilemma: Non-Profit Organisations' Relations with the State in Post-Apartheid South African.” Africanus 40 (2): 3-17.

Flanigan, S. 2011. "Barriers to Immigrant Engagement with Government: Perceptions from Immigrant Nonprofit Organizations in California and New York State." Journal of Public Management and Social Policy 17 (2): 63-80.

Freeman, E. R. 1984. Strategic Management: A Stakeholder Approach. Marshfield: Pitman Publishing.

Frumkin, P. 2002. On Being Nonprofit: a Conceptual and Policy Primer. Cambridge: Harvard University Press.

Gaventa, J. 2004. "Towards Participatory Governance: Assessing the Transformation Possibilities." In Participation: From Tyrany to Transformation? Exploring New Approaches to Participation in Development, edited by S. Hickey, and G. Mohan, 25-41. London: Zed Books.

Glaser, B. G., and A. Strauss. 1967. The Discovery of Grounded Theory. Chicago: Aldine Publishing Company.

Göçmen, I. 2013. "The Role of Faith-Based Organizations in Social Welfare Systems: A Comparison of France, Germany, Sweden, and the United Kingdom." Nonprofit and Voluntary Sector Quarterly 42 (3): 495-516.

Goulet, D. 1989. “Participation in Development: New Avenues.” World Development 17 (2): 165-78.

Grimble, R., and K. Wellard. 1997. "Stakeholder Methodologies in Natural Resource Management: a Review of Principles, Contexts, Experiences and Opportunities." Agricultural Systems 55 (2): 173-93.

Jiwani, I. 2000. "Globalization at the Level of the Nation-State: The Case of Canada's Third Sector." Innovations: A Journal of Politics 3: 27-46.

Joffe, H. 2012. "Thematic Analysis." In Qualitative Research Methods in Mental Health and Psychotherapy: A Guide for Students and Practitioners, edited by D. Harper, and A. Thompson, 210-23. Chichester: Wiley-Blackwell.

Kendall, J., and M. Knapp. 1993. Defining the Nonprofit Sector: The United Kingdom. Working Papers of Johns Hopkins Comparative Nonprofit Sector Project. Also available at https://citeseerx.ist.psu.edu/viewdoc/download?doi=10.1.1.473.7586\&rep=rep1\&type=pdf.

Kersting, N. 2013. “Online Participation: From 'Invited' to 'Invented' Spaces.” International Journal of Electronic Governance 6 (4): 270-80.

Krasnopolskaya, I., Y. Skokova, and U. Pape. 2015. “Government-Nonprofit Relations in Russia's Regions: An Exploratory Analysis.” VOLUNTAS: International Journal of Voluntary and Nonprofit Organizations 26 (6): 2238-66.

Levy, K., and A. Ketels. 2021. "Outsourcing and Networking: Similar Trends in Local State-NPO Cooperation in Germany and China." Nonprofit Policy Forum 12 (2): 243-84.

Lyon, A., P. Hunter-Jones, and G. Warnaby. 2017. “Are We Any Closer to Sustainable Development? Listening to Active Stakeholder Discourses of Tourism Development in the Waterberg Biosphere Reserve, South Africa." Tourism Management 61: 234-47.

Mafunisa, M. J. 2004. "The Role of Civil Society in Promoting Good Governance in the Republic of South Africa." International Review of Administrative Sceinces 70 (3): 489-96. 
Mitchell, R. K., B. R. Agle, and D. J. Wood. 1997. "Toward a Theory of Stakeholder Identification and Salience: Defining the Principle of Who and What Really Counts." Academy of Management Review 22 (4): 853-86.

Mosley, J. E. 2020. "Social Service Nonprofits: Navigating Conflicting Demands." In The Nonprofit Sector, edited by W. W. Powell, and P. Bromley, 251-70. California: Stanford University Press.

Muhr, T. 1991. "ATLAS/ti-A Prototype for the Support of Text Interpretation." Qualitative Sociology 14 (4): 349-71.

Murombo, T. 2008. "Beyond Public Participation: The Disjuncture Between South Africal's Environmental Impact Assessment (EIA) Law and Sustainable Development." Potchefstroom Electronic Law Journal/Potchefstroomse Elektroniese Regsblad 11 (3): 1-31.

Nicholson-Crotty, J. 2007. "Politics, Policy, and the Motivations for Advocacy in Nonprofit Reproductive Health and Family Planning Providers." Nonprofit and Voluntary Sector Quarterly 36 (1): 5-21.

Nwauche, S., and F. Claeyé. 2019. "Institutional Voids: Impediment to the Achievement of the Sustainable Development Goals in South African Municipalities." Presented at the: United Nations Task Force on Social and Solidarity Economy (UNTFSSE) Conference, Geneva, Switzerland, 25-26 June, 2019, 1-13. Geneva: United Nations Research Institute for Social Development (UNRISD). Also available at http://unsse.org/knowledge-hub/institutionalvoids.

Okuyama, N, Y. Ishida, and N. Yamauchi. 2010. "Public Private Partnership between Local Governments and Nonprofits in Japan." Nonprofit Policy Forum 1 (1): 1-21.

Patel, L. 2012. "Developmental Social Policy, Social Welfare Services and the Non-Profit Sector in South Africa." Social Policy \& Administration 46 (6): 603-18.

Piper, L., and L. Nadvi. 2010. "Popular Mobilization, Party Dominance and Participatory Governance in South Africa." In Citizenship and Social Movements: Perspectives from the Global South, 10, edited by L. Thompson, and C. Tapscott, 212-38. London: Zed.

Republic of South Africa. 2000. Local Government: Municipal Systems Act 32 of 2000. Also available at http://www.msukaligwa.gov.za/MsukWeb/Documents/Acts/LOCAL\% 20GOVERNMENT\%20MUNICIPAL\%20SYSTEMS\% 20.

Republic of South Africa. 2018. Integrated Planning Framework Bill. Also available at https://www. gov.za/sites/default/files/gcis_document/201805/integrated-planning-framework-bill.

Republic of South Africa. n.d. A Concept Note on Institutionalization of Planning in South Africa. Also available at https://www.dpme.gov.za/keyfocusareas/gwmeSite/Goverment.

Salamon, L. M. 1994. “The Rise of the Nonprofit Sector.” Foreign Affairs: 109-22, https://doi.org/ $10.2307 / 20046747$.

Salamon, L. M. 1995. Partners in Public Service: Government-Nonprofit Relations in the Modern Welfare State. Baltimore: The Johns Hopkins University Press.

Salamon, L. M., H. K. Anheier, R. List, S. Toepler, and W. S. Sokolowski. 1999. Global Civil Society: Dimensions of the Nonprofit Sector. Baltimore: The Johns Hopkins Centre for Civil Society Studies.

Salamon, L. M., and S. Toepler. 2015. "Government-Nonprofit Cooperation: Anomaly or Necessity?” Voluntas: International Journal of Voluntary and Nonprofit Organizations 26 (6): 2155-77.

Savage, G. T., T. W. Nix, C. J. Whitehead, and J. D. Blair. 1991. "Strategies for Assessing and Managing Organizational Stakeholders." Academy of Management Executives 5 (2): 61-75.

Shier, M. L., and J. R. Graham. 2014. "Social Policy in Canada." In Encyclopedia of Social Work, 1-13. New York, NY: Oxford University Press. 
Smith, S. R., and M. Lipsky. 1993. "Nonprofits for Hire: The Welfare State in the Age of Contracting." Cambridge, MA: Harvard University Press.

Struyk, R. J. 2002. "Nonprofit Organizations as Contracted Local Social Service Providers in Eastern Europe and the Commonwealth of Independent States." Public Administration and Development: The International Journal of Management Research and Practice 22 (5): 429-37.

Toepler, S., A. Zimmer, C. Fröhlich, and K. Obuch. 2020. "The Changing Space for NGOs: Civil Society in Authoritarian and Hybrid Regimes." VOLUNTAS: International Journal of Voluntary and Nonprofit Organizations 31 (4): 649-62.

Tshiyoyo, M. 2019. "Non-Governmental Organisations as Alternatives for Service Delivery in Contemporary States." International Journal of Management Practice 12 (1): 127-46.

Verschuere, B., and J. De Corte. 2015. "Nonprofit Advocacy Under a Third-Party Government Regime: Cooperation or Conflict?" VOLUNTAS: International Journal of Voluntary and Nonprofit Organizations 26: 222-41.

Williams, J. J. 2005. "Community Participation and Democratic Practice in Post-Apartheid South Africa: Rhetoric versus Reality.” Critical Dialogue: Public Participation in Review 2 (1): 19-27, 05.

World Bank. 1992. Governance and Development. Washington: World Bank.

World Bank. 1994. Development in Practice. Governance. Washington: The World Bank's Experience.

Zhu, Z., R. Zhao, and C. Tao. 2021. "Chinese NPOs in Service Contracting at the Community Level: Challenges and Strategies." VOLUNTAS: International Journal of Voluntary and Nonprofit Organizations 32: 780-94.

Zimmer, A. 1999. "Corporatism Revisited-The Legacy of History and the German Nonprofit Sector." Voluntas: International Journal of Voluntary and Nonprofit Organizations 10 (1): 37-49.

Zimmer, A. 2015. “Germany’s Nonprofit Organizations: Continuity and Change.” Sociologia e Politiche Sociali 18 (3): 9-26. 